\title{
Occurrence of Synthetic Phenolic Antioxidants and Major Metabolites in Municipal Sewage Sludge in China
}

\author{
Runzeng Liu, Shanjun Song, Yongfeng Lin, Ting Ruan,* and Guibin Jiang
}

State Key Laboratory of Environmental Chemistry and Ecotoxicology, Research Center for Eco-Environmental Sciences, Chinese Academy of Sciences, Beijing 100085, China

\section{Supporting Information}

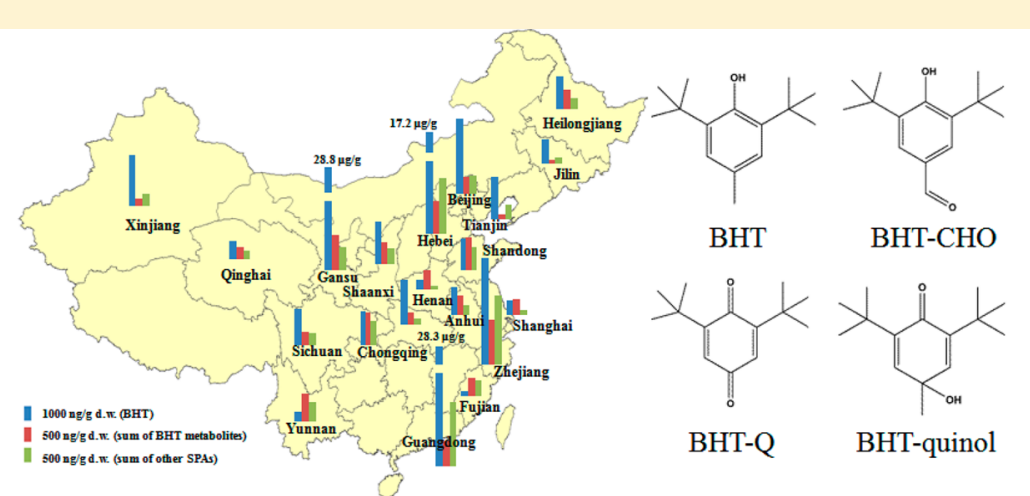

ABSTRACT: Synthetic phenolic antioxidants (SPAs) are one group of widely used additive chemicals, which have not yet had focused attention except for a few compounds such as 2,6-di-tert-butyl-4-methylphenol (BHT). In this study, the occurrence and composition profiles of 12 frequently used SPAs and three BHT metabolites were investigated in fifty-six sludge samples collected from individual wastewater treatment plants in China. Eleven SPAs were positively found in the sludge samples, in which, to our knowledge, eight SPA compounds were identified for the first time in the environment. BHT, 4-tert-octylphenol (4$t \mathrm{OP}$ ), and 2,4,6-tri-tert-bultylphenol ( $\mathrm{AO} 246$ ) were the most dominant SPAs in the sludge at mean concentrations of $4.14 \mu \mathrm{g} / \mathrm{g}$, $374 \mathrm{ng} / \mathrm{g}$, and $98.1 \mathrm{ng} / \mathrm{g}$ d.w. (dry weight). Meanwhile, three BHT metabolites, including 3,5-di-tert-butyl-4hydroxybenzaldehyde (BHT-CHO), 2,6-di-tert-butyl-1,4-benzoquinone (BHT-Q), and 2,6-di-tert-butyl-4-hydroxy-4-methyl2,5-cyclohexadienone (BHT-quinol), were also found in most of the samples (>98.2\%) with mean concentrations of 141, 562, and $225 \mathrm{ng} / \mathrm{g}$ d.w., respectively. The activated sludge system (anaerobic, anoxic, and oxic tanks) of a wastewater treatment plant was further investigated for the removal efficiencies of the SPAs. High removal efficiencies $(80.1-89.2 \%)$ were found for the six detected SPAs in the aqueous phase, while generation of large proportions of the three BHT metabolites was also observed.

\section{INTRODUCTION}

Synthetic phenolic antioxidants (SPAs) are a group of chemicals which present a basic common structure characterized by phenolic rings typically substituted with hindered alkyl groups in ortho-positions. ${ }^{1}$ These chemicals are largely used in rubber, elastomers, plastic, cosmetic formulations, pharmaceuticals, and food applications to retard the oxidation process. ${ }^{2,3}$ It was reported that 2,6-di-tert-butyl-4-methylphenol (BHT), which is the most frequently used SPA, was added in various kinds of finished food and more than 1700 cosmetic formulations with contents up to $0.5 \% .^{3}$ The wide use of SPA compounds triggered an increasing concern on their potential toxicity effects. 4-tert-Octylphenol (4-tOP) was reported to have an estrogenic effect in in vivo and in vitro studies. ${ }^{4-6}$ Strong endocrine activity of 4,4'-butylidenebis(3-methyl-6-tertbutylphenol) (AO 44B25) was also found in the in vivo test. ${ }^{7}$ The International Agency for Research on Cancer (IARC) has evaluated 3-tert-butyl-4-methoxyphenol (BHA) and found sufficient evidence for its carcinogenicity in experimental animals. ${ }^{8,9}$ Though the effect of BHT consumption on human health still remained controversial, ${ }^{10,11}$ some BHT metabolites may pose a health risk as they were reported to generate peroxides in mice and rats and may induce cellular DNA damage or have the capacity to be cancer initiators. ${ }^{12}$

Few studies have investigated the occurrence of SPA analogues in the environment, among which the pollution of BHT received the most attention. BHT was found in indoor dust, natural waters, and sewage influent and effluent with concentrations ranging from part-per-trillion (ppt) to part-permillion (ppm). ${ }^{13-16}$ Using time-of-flight mass spectrometry for nontarget screening of organic pollutants, BHT was positively identified in surface water and soil samples collected from a rice production area in Columbia. ${ }^{17} \mathrm{BHA}$ and 4-tOP were also

Received: October 21, 2014

Revised: January 16, 2015

Accepted: January 21, 2015

Published: January 21, 2015 


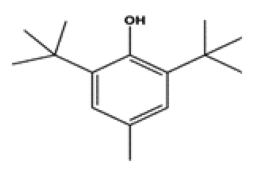

2,6-di-tertbutyl-4-methylphenol (BHT, 128-37-0)

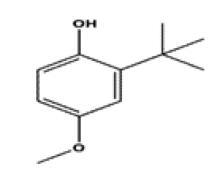

3-tert-butyl4-methoxyphenol (BHA, 121-00-6)

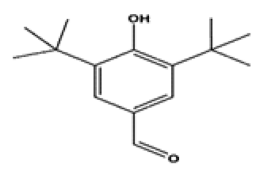

3,5-di-tert-butyl-4hydroxybenzaldehyde (BHT-CHO, 1620-98-0)<smiles>CC(C)(C)C1=CC(=O)C=C(C(C)(C)C)C1=O</smiles>

2,6-di-tert-butyl1,4-benzoquinone (BHT-Q, 719-22-2)

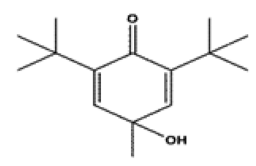

2,6-di-tert-butyl-4-hydroxy4-methyl-2,5-cyclohexadienone (BHT-quinol, 10396-80-2)

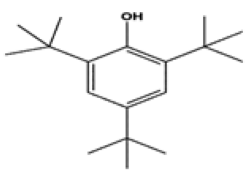

2,4,6-tri-

tert-butylphenol (AO 246, 732-26-3)

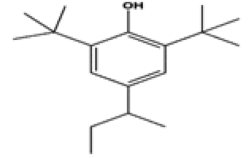

2,6-di-tert-

butyl-4-sec-butylphenol (DTBSBP, 17540-75-9)

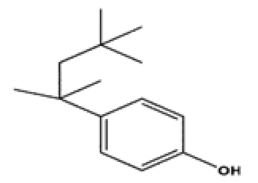

4-tertoctylphenol (4-tOP, 140-66-9)<smiles>CCc1cc(Cc2cc(CC)cc(C(C)(C)C)c2O)c(O)c(C(C)(C)C)c1</smiles>

2,2-methylenebis (4-ethyl-6-tert-butylphenol) (AO 425, 88-24-4)<smiles>CCCC(c1cc(O)c(C(C)(C)C)cc1C)c1cc(C(C)(C)C)c(O)cc1C</smiles>

4,4'-butylidenebis (3-methyl-6-tert-butylphenol) (AO 44B25, 85-60-9)<smiles>CC(C)(C)c1cc(Cc2cc(C(C)(C)C)c(O)c(C(C)(C)C)c2)cc(C(C)(C)C)c1O</smiles>

4,4'-methylenebis (2,6-di-tert-butylphenol) (AO 4426, 118-82-1)<smiles>Cc1cc(Cc2cc(C)cc(C(C)(C)C)c2O)c(O)c(C(C)(C)C)c1</smiles>

2,2'-methylenebis (6-tert-butyl-4-methylphenol) (AO 2246, 119-47-1)

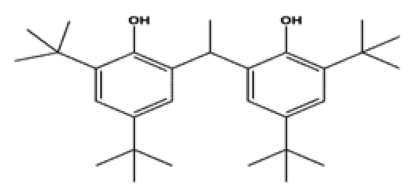

2,2'-ethylidenebis (4,6-di-tert-butylphenol) (AO 22E46, 35958-30-6)

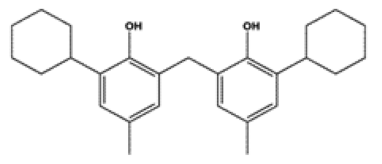

2,2'-methylenebis (6-cyclohexyl-4-methyl)phenol (AO ZKF, 4066-02-8)

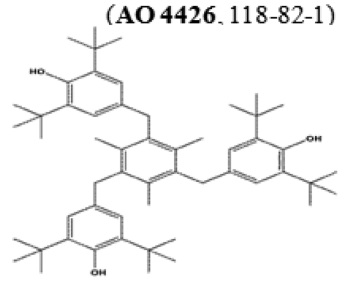

1,3,5-trimethyl-2,4,6-tris(3,5-ditert-butyl-4-hydroxybenzyl)benzene (AO 330, 1709-70-2)

Figure 1. Chemical name, CAS registry number, and structure of SPA analogues and relevant metabolites.

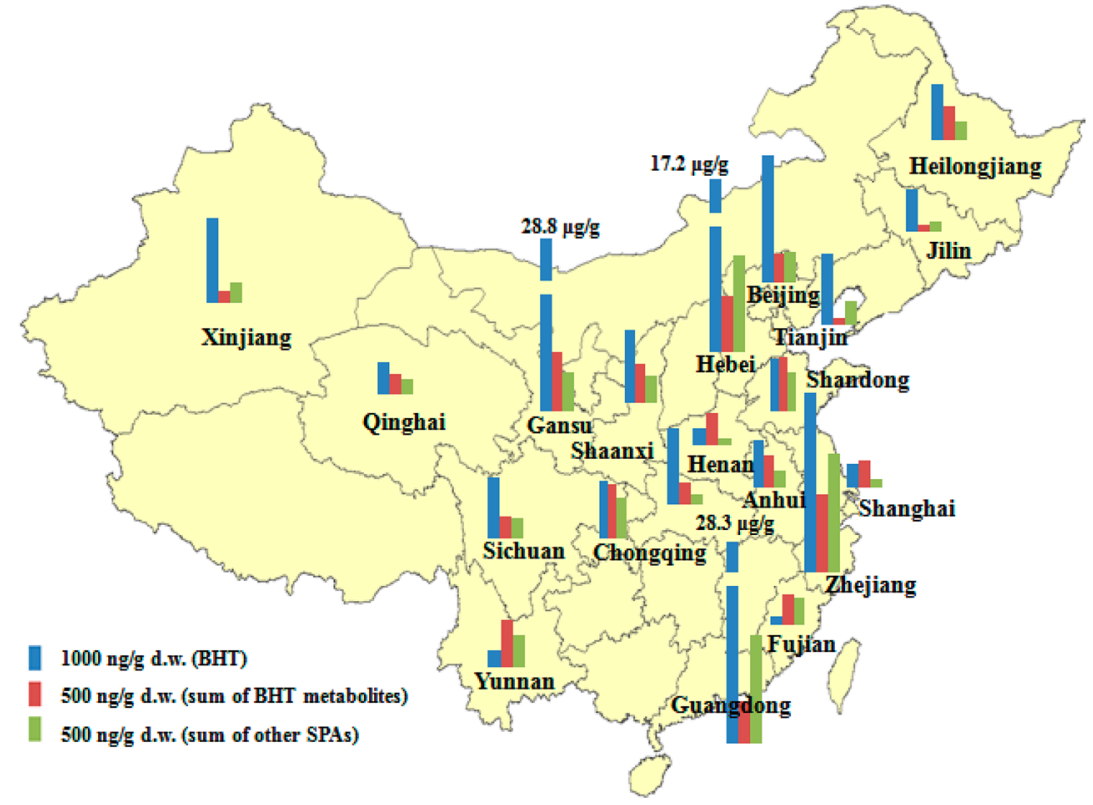

Figure 2. Sampling locations and spatial distributions of the concentrations of SPA analogues and metabolites in municipal sewage sludge samples in China (mean concentration values of different SPA analogues and metabolites were present for sludge samples in the same provinces).

positively identified in house dust and various water matrices including sewage influent, surface water, and groundwater. ${ }^{18-22}$ Besides, migrations of BHT, BHA, and 2,2'-methylenebis(4methyl-6-tert-butylphenol) (AO 2246) were found from plastic packaging materials to food simulates (distilled water, $3 \%$ acetic acid, $10 \%$ ethanol and oil), which were incubated at $40{ }^{\circ} \mathrm{C}$ for 10 days. $^{20}$ Nevertheless, as for other SPAs as well as relevant metabolites, little information was available on their occurrence and residue levels in environment compartments.

Based on the hydrophobic property of the SPA compounds ( $\log K_{\mathrm{ow}}$ in the range of 3.50 (BHA) to 17.17 (1,3,5-trimethyl- 2,4,6-tris(3,5-di-tert-butyl-4-hydroxybenzyl)benzene, $\mathrm{AO}$ $330)){ }^{23}$ sewage sludge in wastewater treatment plants (WWTPs) could be sufficient to track the occurrence of emerging SPAs at a large geographical scale. In the present work, municipal sewage sludge samples were collected from different Chinese cities to provide valuable information on the presence, contamination levels, and distribution patterns of SPAs in the ambient environment in China. Influent, effluent, and sludge samples of the activated sludge system in one WWTP were further collected and analyzed to give a first 
impression on its biotransformation and removal behaviors of target SPA analytes.

\section{MATERIALS AND METHODS}

Materials. Analyte name, structure and other relevant data are shown in Figure 1. BHT-quinol was supplied by Frontier Scientific Inc. (Logan, USA). AO 22E46 was supplied by AccuStandard (New Haven, USA). Certified standards of other analytes were obtained from TCI (Tokyo, Japan). The purities for all the target analytes were $>95 \%$. Isotope-labeled 2,6 di(tert-butyl-d9)-4-methyl(phenol-3,5,O-d3) (BHT-d21) and ${ }^{13}$ C-tetrabromobisphenol A $\left({ }^{13} \mathrm{C}_{12}\right.$-TBBPA) were obtained from Cambridge Isotope Laboratories (Andover, USA). Stock standard solutions $(1000 \mu \mathrm{g} / \mathrm{mL})$ were individually prepared in methanol, and intermediate solutions were weekly prepared from the stock standard solutions by appropriate methanol dilution. Silica gel (100-200 mesh size, Merck, Darmstadt, Germany) was activated at $550{ }^{\circ} \mathrm{C}$ for $12 \mathrm{~h}$ and $5 \%$ waterdeactivated prior to use. Anhydrous sodium sulfate $\left(\mathrm{Na}_{2} \mathrm{SO}_{4}\right)$ was baked at $600{ }^{\circ} \mathrm{C}$ for $6 \mathrm{~h}$ and stored in a sealed desiccator. Pesticide residue grade dichloromethane (DCM), hexane (Hex), and methanol $(\mathrm{MeOH})$ were purchased from J.T. Baker (Phillipsburg, USA). Ultrapure water $(18.3 \mathrm{M} \Omega \times \mathrm{cm})$ was generated by a Milli-Q purification system (Millipore, Billerica, USA).

Sample Collection. Fifty-six WWTP sludge samples were collected from 33 cities in 20 provinces in China during October 2010 to May 2011 (Figure 2). Approximately $500 \mathrm{~g}$ of freshly digested sludge was collected at the dewatering process, packed in aluminum foil, sealed in a polypropylene bag, and express-delivered to our lab immediately. All sludge samples were freeze-dried, homogenized, sieved through a stainless steel 100 -mesh sieve, and then stored in $-20{ }^{\circ} \mathrm{C}$ until analysis. Details are given in the Supporting Information (SI, Table S1). Influent and effluent samples of the secondary treatment step were taken from a WWTP everyday during March 24-26, 2014. The WWTP investigated in this work is located in Beijing, China and has a conventional activated sludge system (anaerobic, anoxic, and oxic tanks) with an average domestic wastewater flow of $200000 \mathrm{~m}^{3} / \mathrm{d}$. The $24 \mathrm{~h}$ composite sewage samples were collected using flow proportional samplers (Global Water Inc., TX). At each site, $500 \mathrm{~mL}$ of water was collected and stored in a brown glass bottle. All vessels were precleaned with $\mathrm{MeOH}$ and ultrapure water to avoid contamination. All water samples were extracted as soon as possible after centrifugation at $5000 \mathrm{rpm}$ for $10 \mathrm{~min}$ to separate liquid/solid phases, and the whole remaining suspended solid matters were also gathered for further instrumental analysis. Sludge samples of secondary clarifier were collected from the WWTP in the three successive days and prepared as above (Table S7).

Sample Preparation and Instrumental Analysis. For sludge samples, approximately $0.5 \mathrm{~g}$ of the sample (spiked with $200 \mathrm{ng}$ of BHT-d21 and $10 \mathrm{ng}$ of ${ }^{13} \mathrm{C}$-TBBPA) was mixed with $15 \mathrm{~g}$ of $\mathrm{Na}_{2} \mathrm{SO}_{4}$ and extracted with DCM/Hex (3:1, v/v) at 90 ${ }^{\circ} \mathrm{C}$ and $1500 \mathrm{psi}$ in three static extraction cycles of $10 \mathrm{~min}$ using an accelerated solvent extractor (ASE 350, Dionex Inc., Sunnyvale, CA). The extracts were concentrated by rotary evaporation to $\sim 2 \mathrm{~mL}$ and fractioned on an $8 \mathrm{~g}$ silica column. The silica column was preconditioned by $30 \mathrm{~mL}$ of Hex before loading, and all analytes were eluted with $120 \mathrm{~mL}$ of DCM/Hex $(1: 1, \mathrm{v} / \mathrm{v})$ mixture. The eluates were then concentrated, solvent exchanged into $5 \mathrm{~mL}$ of $\mathrm{MeOH}$, and transferred to LC vials.
Finally, $20 \mu \mathrm{L}$ of the sample was injected into the instrument for quantification analysis. The water samples were extracted using a liquid-liquid extraction method. Briefly, a $400 \mathrm{~mL}$ sample (spiked with $200 \mathrm{ng}$ of BHT-d21 and $10 \mathrm{ng}$ of ${ }^{13} \mathrm{C}$ TBBPA) was mixed with $100 \mathrm{~mL}$ of DCM and shaken for 5 min. Then the DCM was transferred to another glass bottle, and the extraction was repeated three times. After extraction, the DCM phases were combined, concentrated by rotary evaporation to $\sim 2 \mathrm{~mL}$, fractionated on the silica gel packed column, and further quantitatively analyzed as described for sludge samples.

An Alliance 2695 high performance liquid chromatograph interfaced with a Quattro Premier XE triple-quadrupole mass spectrometer (HPLC-MS/MS, Waters, Milford, MA) was used for the determination of the SPAs. A $150 \times 2.1 \mathrm{~mm}$ SymmetryShield $5 \mu \mathrm{m}$ C18 analytical column (Waters, Milford, USA) was chosen for chromatographic separation. Column temperature was set at $40{ }^{\circ} \mathrm{C}$. $\mathrm{MeOH}$ (A) and ultrapure water (B) were chosen as mobile phases. The gradient was initiated at a composition of 25:75 (A:B, v/v) and was first held for $5 \mathrm{~min}$. Then the gradient elution program was optimized with composition A linearly increased to $100 \%$ in $10 \mathrm{~min}$ and then held for $10 \mathrm{~min}$. After immediately returning to the initial composition of $25: 75$, the column was allowed to re-equilibrate for $3 \mathrm{~min}$, which gave a total analysis time of $23 \mathrm{~min}$. Flow rate for the separation procedure was set at $0.3 \mathrm{~mL} / \mathrm{min}$. The mass spectrometer was operated in negative electrospray ionization (ESI) mode. The source and desolvation temperature were set at 120 and $450{ }^{\circ} \mathrm{C}$, respectively. Desolvation gas flow was 800 $\mathrm{L} / \mathrm{h}$, cone gas flow was $50 \mathrm{~L} / \mathrm{h}$, while argon pressure in the collision cell was kept at $3.8 \times 10^{-3}$ mbar for MS/MS measurement. Detailed information on the optimized parameters and monitored ion transitions for each analyte is given in Table S3.

Quality Assurance/Quality Control. For the evaluation of extraction efficiency, 10 sludge samples and 2 water samples were randomly selected for a fourth extraction after the first three extraction cycles. No quantifiable amounts of target compounds were detected in the fourth extractions, which suggested high efficiencies of the first three extractions for both sludge and water samples. Relative recoveries of the target analytes in matrix-spiked sewage water $(100 \mathrm{ng} / \mathrm{L})$ and sludge samples (200 ng/g) were 61.0-105\% and 65.0-103\%, respectively (Table S4). Matrix effects for the target analytes were calculated by the percentage of signal response in sample matrix versus the signal of the same concentration in $\mathrm{MeOH}$. No severe ionization suppression/enhancement was found for all the analytes in sewage water and sludge matrices, with matrix effects within the range of 85.3 (4-tOP) $-110 \%$ (AO 2246). The relative standard deviations ( $\mathrm{RSD}, n=5)$ for the water and sludge matrices were all less than $17.0 \%$. One procedural blank of $15 \mathrm{~g}$ of $\mathrm{Na}_{2} \mathrm{SO}_{4}$ (for solid samples) or $400 \mathrm{~mL}$ of ultrapure water (for water samples) was included in every batch of samples $(n=8)$ to monitor for background contamination levels. All analytes in the blanks were under the quantification limits. Quantification of the analytes was based on an external calibration curve, and two internal standards were used to correct the possible target losses during the sample preparation. Instrumental calibration was verified by injection of 7 calibration standards (ranging from 20 to $2000 \mathrm{ng} / \mathrm{mL}$ for BHT, 0.5 to $100 \mathrm{ng} / \mathrm{mL}$ for others), and the linearity of the calibration curve $\left(r^{2}\right)$ was $>0.99$. For samples with analyte concentrations beyond the linear dynamic range, $\mathrm{MeOH}$ 
Table 1. Descriptive Statistics of the Measured Concentrations (ng/g, d.w.) of SPAs and Relevant Metabolites in Sludge Samples

\begin{tabular}{|c|c|c|c|c|c|}
\hline compounds & $\mathrm{GM}^{a}$ & median & range & $\mathrm{DR}^{b}(\%)$ & averaged proportion (\%) \\
\hline $\mathrm{BHT}$ & $4.14 \mathrm{e} 3$ & $2.35 \mathrm{e} 3$ & $51.7-30.3 \mathrm{e} 3$ & 100 & 83.4 \\
\hline BHA & 3.58 & 2.44 & $<\mathrm{MQL}-17.4$ & 66.1 & 0.07 \\
\hline 4-tOP & 317 & 85.4 & $<\mathrm{MQL}-8.57 \mathrm{e} 3$ & 92.8 & 6.39 \\
\hline AO 246 & 374 & 244 & $9.28-1.70 \mathrm{e} 3$ & 100 & 7.54 \\
\hline DTBSBP & 98.1 & 77.8 & $2.32-461$ & 100 & 1.98 \\
\hline AO 2246 & 3.53 & 0.75 & $<$ MQL-91.3 & 53.5 & 0.07 \\
\hline $\mathrm{AO} 22 \mathrm{E} 46$ & 0.43 & 0.14 & $<\mathrm{MQL}-5.50$ & 21.4 & 0.01 \\
\hline AO 330 & 11.4 & 4.33 & $<\mathrm{MQL}-262$ & 89.3 & 0.23 \\
\hline $\mathrm{AO} 425$ & 0.11 & 0.07 & $<\mathrm{MQL}-2.04$ & 8.93 & 0.002 \\
\hline AO 4426 & 2.86 & 1.13 & $<$ MQL-97.9 & 1.78 & 0.06 \\
\hline $\mathrm{AO} 44 \mathrm{~B} 25$ & 11.0 & 3.92 & $<\mathrm{MQL}-174$ & 69.6 & 0.22 \\
\hline ВНТ-СHO & 141 & 112 & $<\mathrm{MQL}-660$ & 98.2 & $c$ \\
\hline BHT-Q & 562 & 345 & $15.5-5.13 \mathrm{e} 3$ & 100 & $c$ \\
\hline BHT-quinol & 225 & 221 & $28.9-848$ & 100 & $c$ \\
\hline
\end{tabular}

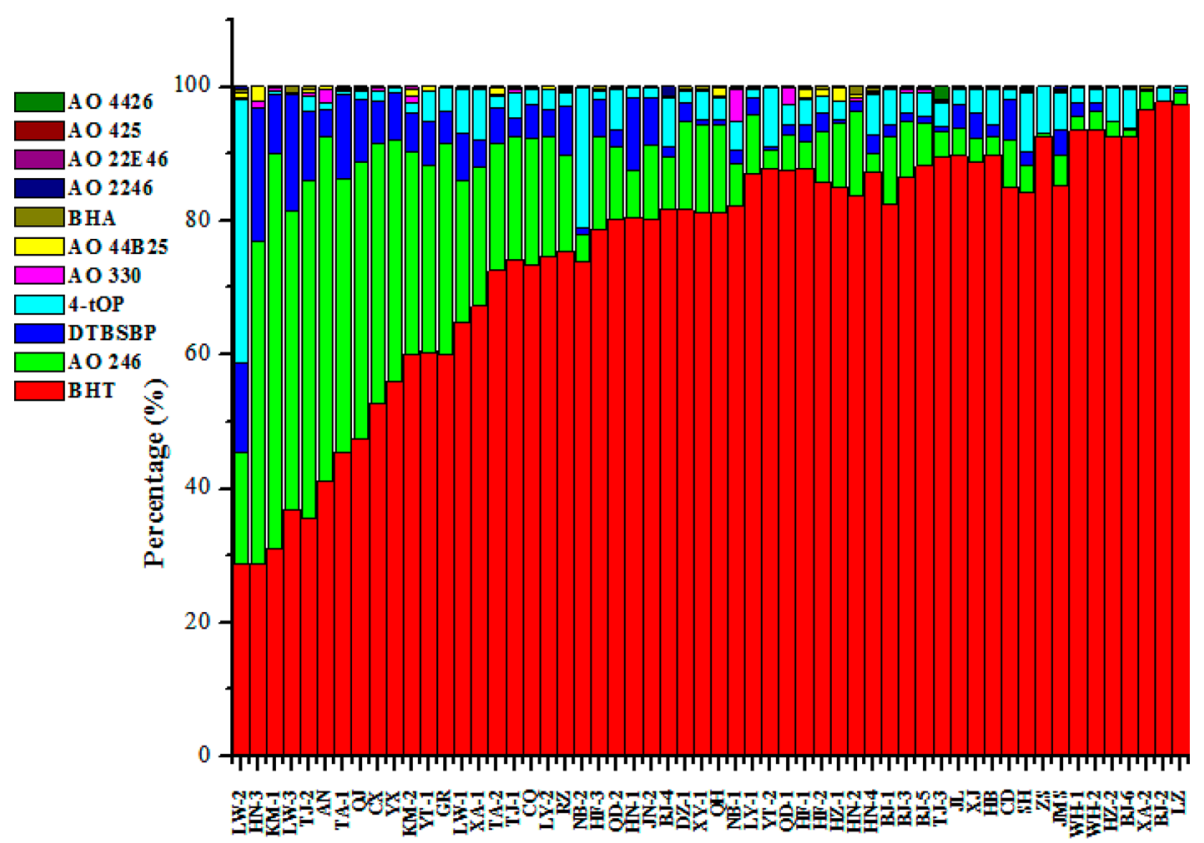

Figure 3. Percentage profiles of individual SPA in each sludge samples.

dilution was carried out. The method quantification limits (MQLs), which were calculated as a signal-to-noise ratio of 10 , were from 0.1 to $25 \mathrm{ng} / \mathrm{L}$ and 0.1 to $15 \mathrm{ng} / \mathrm{g}$ for sewage water and sludge matrices, respectively (Table S4).

Statistical Analysis. Geometric mean, median, and concentration ranges were used to describe the results. All data were reported on a dry weight (d.w.) basis. Analyte concentrations under MQLs were set as MQL divided by the square root of 2. Statistical analyses were conducted using SPSS V17.0 for Windows Release (SPSS Inc., 2009). The correlations among the log-transformed concentrations of different SPA compounds were assessed by the Pearson's correlation analysis. $\mathrm{AO}$ 22E46, $\mathrm{AO} 425$, and AO 4426 were excluded in the statistical analysis due to their low detection frequencies. All the statistical significant levels were set at $p<0.05$, unless otherwise mentioned. The total concentration of SPAs was the sum concentrations of all the target antioxidants analyzed in this study, whereas the BHT metabolites were not included. The composition profiles of the target SPAs were calculated as geometric mean concentration of individual SPA divided by the $\sum$ SPAs concentration.

\section{RESULTS AND DISCUSSION}

Concentrations and Composition Profiles of the Target SPAs in Sludge. The concentrations of the target SPAs in the sludge samples are presented in Table 1 and the SI (Table S1), while the percent stacked columns of the detected SPA congeners are shown in Figure 3. Except for AO ZKF, the 11 other SPAs could be positively identified in the sludge samples with concentrations ranging from $<$ MQLs to $30.3 \mu \mathrm{g} / \mathrm{g}$ d.w. As shown in Figure 2, no obvious geographic trends were found for the target analytes. Total concentrations of SPAs (sum of the 11 SPAs, $\sum$ SPAs) in sludge samples ranged from $183 \mathrm{ng} / \mathrm{g}$ to $41.0 \mu \mathrm{g} / \mathrm{g}$, with an average value of $4.96 \mu \mathrm{g} / \mathrm{g}$. BHT was the most dominant SPA analogue, which constituted 28.7-97.7\% (average $83.4 \%$ ) of $\sum$ SPAs. It was followed by AO 246 (average 7.54\%), 4-tOP (average 6.39\%), DTBSBP (average 1.98\%), AO 330 (average 0.23\%), AO 44B25 (average 
$0.22 \%$ ), and BHA (average 0.07\%). BHT, AO 246, and DTBSBP were detected in all the investigated samples, while the detection frequencies for 4- $t \mathrm{OP}, \mathrm{AO} 44 \mathrm{~B} 25, \mathrm{AO} 330, \mathrm{BHA}$, and AO 2246 were $92.8 \%, 69.6 \%, 89.3 \%, 66.1 \%$, and $53.5 \%$, respectively. The high detection frequencies of these SPAs demonstrated their wide usage in China. Low detection frequency $(12 / 56)$ was found for $\mathrm{AO} 22 \mathrm{E} 46$. AO 425 was only detectable in five samples, while AO 4426 was only found in one sample, which indicated that both of the compounds might only have limited production and usage in China.

As shown in Table 1, the concentrations of BHT ranged from $51.7 \mathrm{ng} / \mathrm{g}$ to $30.3 \mu \mathrm{g} / \mathrm{g}$ (GM: $4.13 \mu \mathrm{g} / \mathrm{g}$, median: $2.35 \mu \mathrm{g}$ / g). BHT has been used as an antioxidant since the 1950s, and approximately 40 countries permit the use of BHT as a food additive. ${ }^{3} \mathrm{~A}$ few studies have already proved the presence of BHT in an aquatic environment in Germany with concentrations of $7-791 \mathrm{ng} / \mathrm{L}^{16}$ A study on indoor dust in Sweden showed that BHT was among the highest concentration contaminates with the mean concentration of $70 \mu \mathrm{g} / \mathrm{g} .{ }^{13}$ The consumption of BHT by food intake and other ways led to its occurrence in the body fat at the mean concentration of 0.23 $\mu \mathrm{g} / \mathrm{g}$ in 11 residents in UK and at $1.30 \mu \mathrm{g} / \mathrm{g}$ in 12 residents in the USA. ${ }^{24}$ The concentrations of AO 246 varied from $9.28 \mathrm{ng} /$ $\mathrm{g}$ to $1.70 \mu \mathrm{g} / \mathrm{g}$ (GM: $374 \mathrm{ng} / \mathrm{g}$, median: $244 \mathrm{ng} / \mathrm{g}$ ) in the investigated sludge samples. AO 246 can be used as a primary antioxidant or as an intermediate in the synthesis of primary antioxidants. $^{25}$ It was reported with high bioconcentration factors (4320-23200 in fish, exposed to $1 \mu \mathrm{g} / \mathrm{L}$ for 8 week $)^{26}$ and was found in vegetables, animal meat, liver, and fish at nanogram per gram level in Japan. ${ }^{25}$ DTBSBP, which is an isomer of $\mathrm{AO} 246$, was also detected with concentrations from 2.32 to $461 \mathrm{ng} / \mathrm{g}$ (GM: $98.1 \mathrm{ng} / \mathrm{g}$, median: $77.8 \mathrm{ng} / \mathrm{g}$ ). DTBSBP was identified as a high priority for assessment of ecological risk in Canada because it meets the ecological categorization criteria for persistence, bioaccumulation potential, and inherent toxicity to aquatic organisms. ${ }^{27}$ Also, both AO 246 and DTBSBP are in the list of Work Plan Chemicals for Assessment During 2013 and 2014 together with bis(2ethylhexyl)-3,4,5,6-tetrabromophthalate, tri(2-chloroethyl)phosphate, and 2-ethylhexyl-2,3,4,5-tetrabromobenzoate by U.S. EPA for ecological risk evaluation. ${ }^{28}$ To our knowledge, there was no empirical data on measured concentrations of $\mathrm{AO}$ 246 and DTBSBP in environmental media previously. 4-tOP, though largely used to produce octylphenol polyethoxylate surfactant, can also be used as primary antioxidant. 4-tOP has been detected in WWTP effluent and sludge samples with concentrations up to $\mu \mathrm{g} / \mathrm{L}$ and $\mu \mathrm{g} / \mathrm{g}$ levels, respectively. ${ }^{21,29}$ Comparable concentrations of 4-tOP (GM: $317 \mathrm{ng} / \mathrm{g}$, median: $85.4 \mathrm{ng} / \mathrm{g}$ ) were also found in this study. BHA was previously reported in surface water, groundwater, and reclaimed water in southern California with concentrations at ng/L levels. ${ }^{22}$ In the present study, BHA was detected in the samples with concentrations ranging from <MQL to $17.4 \mathrm{ng} / \mathrm{g}$ (GM: 3.58 $\mathrm{ng} / \mathrm{g}$, median: $2.44 \mathrm{ng} / \mathrm{g}$ ). A weak estrogenic effect of BHA was reported in vitro study. ${ }^{30}$ Besides, BHA is included in the Contaminant Candidate List 3 (CCL 3 ) by the U.S. EPA. ${ }^{31}$

Other SPAs with more than one phenolic ring (AO 44B25, $\mathrm{AO}$ 330, $\mathrm{AO} 2246, \mathrm{AO} 22 \mathrm{E} 46, \mathrm{AO} 425$, and $\mathrm{AO} 4426$ ) were also detected in the collected samples with varying concentrations (<MQLs-262 ng/g). AO 44B25, which was reported to have androgenic effect and genetic toxicity, ${ }^{7}$ was detected with concentrations from $<\mathrm{MQL}$ to $174 \mathrm{ng} / \mathrm{g}$ (GM: $11.0 \mathrm{ng} / \mathrm{g}$, median: $3.92 \mathrm{ng} / \mathrm{g})$. The concentrations of $\mathrm{AO} 330$ ranged from <MQL to $262 \mathrm{ng} / \mathrm{g}$ (GM: $11.4 \mathrm{ng} / \mathrm{g}$, median: $4.33 \mathrm{ng} / \mathrm{g}$ ). AO 2246 was detected with GM and median concentration of 3.53 and $0.75 \mathrm{ng} / \mathrm{g}$, respectively. AO 22E46, AO 425, and AO 4426 were detected with concentrations varying from $<$ MQLs to dozens of ng/g level. To our knowledge, no previous data in literature was available on their concentrations in environmental matrices for AO 44B25, AO 330, AO 2246, AO 22E46, $\mathrm{AO}$ 425, and $\mathrm{AO} 4426$.

The six sludge samples collected from different WWTPs in Beijing showed different contamination levels with $\sum$ SPAs varying from 3.61 to $9.76 \mu \mathrm{g} / \mathrm{g}$, indicating that many factors including daily wastewater processing volume and biological treatment techniques might impact the concentrations of SPAs. Besides, the six WWTPs in Beijing serve different districts, which might have different SPA emissions. The observed composition pattern in the sludge samples was well corresponded to the SPA production volumes in China. BHT dominated the SPA concentration profile ( $83.4 \%$ of $\sum$ SPAs) in the investigated sewage sludge samples. This is quite consistent with the BHT usage, which was reported to account for $80 \%$ of the total SPAs with a production volume of $23.3 \mathrm{kt} / \mathrm{a}$ in $1998 \mathrm{in}$ China. ${ }^{32}$ Pearson correlation analysis was performed on the logtransformed concentrations of SPA compounds. Table S5 shows that BHT was significantly correlated with AO 2246, 4tOP, and AO 44B25 $(r=0.357-0.784, p<0.01)$. 4-tOP was significantly correlated with AO $2246(r=0.497, p<0.01)$ and AO 44B25 $(r=0.399, p<0.01)$. AO 246 showed a similar relationship with DTBSBP $(r=0.741, p<0.01)$ and AO 44B25 $(r=0.435, p<0.01)$. AO 2246 was significantly correlated with AO 44B25 $(r=0.350, p<0.01)$ and AO $330(r=0.394, p<$ $0.01)$, and a similar relationship was found between DTBSBP and AO 44B25 $(r=0.399, p<0.01)$. Strong correlation between concentrations of different environmental contaminants might suggest common sources and/or similar environmental fates.

More Toxic BHT Degradation Metabolites in Sludge. In vivo and in vitro metabolism studies of $\mathrm{BHT}$ revealed two main metabolic processes which include oxidation of both the alkyl substituent and aromatic ring system. ${ }^{33}$ Oxidation of the alkyl substituent will lead to $\mathrm{BHT}-\mathrm{CHO}$, while oxidation of the aromatic ring of $\mathrm{BHT}$ leads to $\mathrm{BHT}-\mathrm{Q}$ and $\mathrm{BHT}$-quinol. $\mathrm{BHT}$ $\mathrm{CHO}$ has also been identified as BHT photoinduced transformation product.

Though the toxicities of BHT metabolites have been largely investigated, a few studies have reported their occurrence in the environment. $^{12,14}$ In the present study, BHT-CHO was detected in $98.2 \%$ of the samples with concentrations from 0.67 to $660 \mathrm{ng} / \mathrm{g}$ (GM: $141 \mathrm{ng} / \mathrm{g}$, median: $112 \mathrm{ng} / \mathrm{g}$ ), which was $3.4 \%$ of BHT in mean concentration. BHT-CHO was detected along with BHT in river, rain, and groundwater samples from Germany with concentrations from several tens to hundreds ng/L. ${ }^{16}$ Another BHT metabolite, BHT-Q, was identified in all the investigated samples with concentrations varying from $15.5 \mathrm{ng} / \mathrm{g}$ to $5.13 \mu \mathrm{g} / \mathrm{g}$ (GM: $562 \mathrm{ng} / \mathrm{g}$, median: $345 \mathrm{ng} / \mathrm{g}$ ), which was $13.6 \%$ of BHT in mean concentration. The mean concentration of BHT-Q in the investigated sludge was higher than all the detected SPAs except for BHT, which ranked the second order in concentration. The mean concentration of BHT-Q is 4 times as high as that of BHTCHO. BHT-Q was once detected in WWTP influents in Spain with the mean concentration of $771 \mathrm{ng} / \mathrm{L}$, which was also higher than BHT-CHO in the same samples. ${ }^{14}$ The highest concentrations of BHT-CHO and BHT-Q were both found in 
Table 2. Concentrations (Mean \pm SD) of SPAs and Relevant Metabolites in Sewage and Sludge Samples Collected in the Investigated WWTP

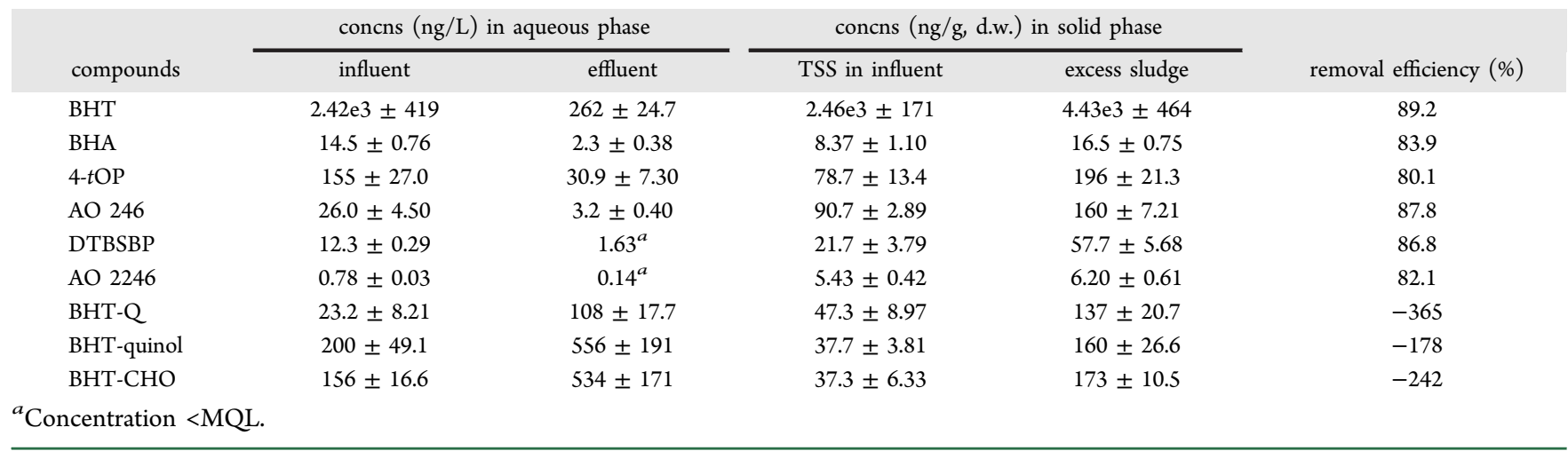

the sample of NB-2, which also contained maximum BHT. BHT-Q can cause DNA damage through $\mathrm{H}_{2} \mathrm{O}_{2}$ and oxygen radical generation, which leads to internucleosomal DNA fragmentation. The lowest concentration of BHT-Q causing DNA cleavage in vitro was quite low $\left(10^{-6} \mathrm{M}\right) .{ }^{34}$ Besides, BHT$\mathrm{Q}$ and $\mathrm{BHT}-\mathrm{CHO}$ were demonstrated to be stable during the WWTP process even when high concentration of chlorine was used. $^{35}$ BHT-quinol, the environmental occurrence of which was not reported previously, was positively identified in all the sludge samples. The concentrations of BHT-quinol varied from 28.9 to $848 \mathrm{ng} / \mathrm{g}$ (GM: $225 \mathrm{ng} / \mathrm{g}$, median: $221 \mathrm{ng} / \mathrm{g}$ ), which accounted for $5.4 \%$ of $\mathrm{BHT}$ in concentration. Significant correlation $(r=0.459, p<0.01)$ between concentrations of $\mathrm{BHT}$ and sum of the three metabolites was also observed in the sludge samples. As shown in Table S6, the predicted overall persistence of the target SPAs by OECD overall persistence and long-range transport potential fugacity screening tool (PovLRTP tool $)^{36}$ ranged from 106 to $519 \mathrm{~d}$, which implied their environmental persistency. The calculated overall persistence of BHT-Q (172 d), BHT-quinol (170 d), and BHT-CHO (108 d) was longer than or equal to their parent compound BHT (108 d). The high environmental persistency and universal occurrence of these BHT metabolites might imply their nonignorable environmental or human health risk. To our knowledge, this is the first study to report the occurrence of BHT metabolites in sludge in China.

Removal of the Detected SPAs by Activated Sludge System. WWTPs in China usually comprise only primary and secondary treatments, with the latter mainly based on conventional activated sludge. ${ }^{37}$ Therefore, investigation on the removal of pollutants through the activated sludge system is important. As shown in Table 2 and Table S7, nine target analytes (six SPAs: BHT, BHA, 4-tOP, AO 246, DTBSBP, and AO 2246; three BHT metabolites: BHT-CHO, BHT-Q, BHTquinol) were detected in total suspended solids (TSS) of the influent with mean concentrations from $5.43 \mathrm{ng} / \mathrm{g}$ to $2.46 \mu \mathrm{g} / \mathrm{g}$. The concentrations of these compounds in excess sludge $(6.20$ $\mathrm{ng} / \mathrm{g}-4.43 \mu \mathrm{g} / \mathrm{g})$ were higher than that in TSS. The nine analytes, which were detected in solid samples, were also found in the collected water samples with concentrations ranging from $<$ MQLs to $2.42 \mu \mathrm{g} / \mathrm{L}$.

Removal efficiencies $(R)$ were calculated on the base of target SPA concentrations in the aqueous phase of influent and effluent samples using the following equation: $R=\left(C_{\text {influent }}-\right.$ $\left.C_{\text {effluent }}\right) / C_{\text {influent }} \times 100 \%$, where $C_{\text {influent }}$ and $C_{\text {effluent }}$ are the target concentrations measured in influent and effluent samples of the activated sludge system, respectively. ${ }^{38}$ As shown in
Table 2, the removal efficiencies of the six detected SPAs in the aqueous phase were $80.1-89.2 \%$, which indicated that the SPA contaminants released into the recipient river from secondary effluent might be minor. Similar phenomenon was found for the hydrophobic benzotriazole ultraviolet stabilizers through the WWTP activated sludge system with removal efficiencies larger than $72 \%{ }^{39}$ The removal efficiencies of BHT metabolites in the aqueous phase were opposite to those of other SPA analytes (Table 2), which indicated the generation of large proportions of these BHT metabolites (178\% for BHT-quinol to $365 \%$ for BHT-Q) in the activated sludge system of the WWTP.

Environmental Implications. In this work, 11 SPAs and three BHT metabolites were positively identified in 56 sewage sludge samples collected from different WWTPs in China, which suggested the prevalent usage of SPA-containing products and widespread occurrence of emerging SPA anthropogenic chemicals in China. This is the first time to report the occurrence of BHT-quinol, AO 246, DTBSBP, AO 2246, AO 22E46, AO 425, AO 44B25, AO 4426, and AO 330 in environmental matrices. Other targets including BHT, BHT$\mathrm{CHO}, \mathrm{BHT}-\mathrm{Q}$ and BHA were reported for the first time in sludge samples in China. Attention should be paid to simultaneous exposure to several SPAs as a synergistic effect was found in the induction of apoptosis between BHT and BHA. $^{40}$ Moreover, the conventional secondary treatment (anaerobic, anoxic, and oxic tanks) of a WWTP was demonstrated to be efficient in removal of SPAs in aqueous phase. However, the concentrations of BHT metabolites in the secondary effluent were much higher than that of in influent, which indicated the generation of BHT metabolites through the activated sludge system. Further studies are needed to discern the release pathways and spatial and temporal distributions and to investigate if additional SPA analogues could also be present in the environment. As the prevalence of more toxic BHT metabolites was reported in the present study, more detailed research is warranted regarding the fate of other SPAs during wastewater treatment procedures as well as their impact on environmental compartments.

\section{ASSOCIATED CONTENT}

\section{S Supporting Information}

Additional tables containing information on the sampling sites and data analysis not presented in the main text. This material is available free of charge via the Internet at http://pubs.acs.org. 


\section{AUTHOR INFORMATION}

\section{Corresponding Author}

*Phone: 8610-6284-9334. Fax: 8610-6284-9179. E-mail: tingruan@rcees.ac.cn.

\section{Notes}

The authors declare no competing financial interest.

\section{ACKNOWLEDGMENTS}

This work was jointly supported by the National Basic Research Program of China (2015CB453102), Chinese Academy of Sciences Grant (Nos. XDB14010400, YSW2013B01), and National Natural Science Foundation (21207140).

\section{REFERENCES}

(1) Brocca, D.; Arivin, E.; Mosbæk, H. Identification of organic compounds migrating from polyethylene pipelines into drinking water. Water Res. 2002, 36 (15), 3675-3680.

(2) Demertzis, P. G.; Franz, R. Development of an HPLC method for measurements of the stability of Irganox-type polymer antioxidants in fatty food simulants. Z. Lebensm.-Unters. -Forsch. A 1998, 206 (3), 193-198.

(3) Lanigan, R. S.; Yamarik, T. A. Final report on the safety assessment of BHT (1). Int. J. Toxicol. 2002, 21 (Suppl 2), 19-94.

(4) Pedersen, S. N.; Christiansen, L. B.; Pedersen, K. L.; Korsgaard, B.; Bjerregaard, P. In vivo estrogenic activity of branched and linear alkylphenols in rainbow trout (Oncorhynchus mykiss). Sci. Total Environ. 1999, 233 (1-3), 89-96.

(5) Madsen, L. L.; Korsgaard, B.; Bjerregaard, P. Estrogenic effects in flounder Platichthys flesus orally exposed to 4-tert-octylphenol. Arch. Tocicol. 2003, 64 (4), 393-405.

(6) Kotula-Balak, M.; Chojnacka, K.; Hejmej, A.; Galas, J.; Satola, M.; Bilinska, B. Does 4-tert-octylphenol affect estrogen signaling pathways in bank vole Leydig cells and tumor mouse Leydig cells in vitro? Reprod. Toxicol. 2013, 39 (1), 6-16.

(7) Satoh, K.; Nonaka, R.; Nakae, D.; Ogata, A. Increase in in utero exposure to a migrant, 4,4'-butylidenebis(6-t-butyl-m-cresol), from nitrile-butadiene rubber gloves on brain aromatase activity in male rats. Biol. Pharm. Bull. 2010, 33 (1), 6-10.

(8) Grice, H. C. Safety evaluation of butylated hydroxyanisole from the perspective of effects on forestomach and oesophageal squamous epithelium. Food Chem. Toxicol. 1988, 26 (8), 717-723.

(9) Whysner, J.; Williams, G. M. Butylated hydroxyanisole mechanistic data and risk assessment Conditional species-specific cytotoxicity, enhanced cell proliferation, and tumor promotion. Pharmacol. Ther. 1996, 71 (1-2), 137-151.

(10) Botterweck, A. A. M.; Verhagen, H.; Goldbohm, R. A.; Kleinjans, J.; van den Brandt, P. A. Intake of butylated hydroxyanisole and butylated hydroxytoluene and stomach cancer risk: results from analyses in the Netherlands cohort study. Food Chem. Toxicol. 2000, 38 (7), 599-605.

(11) Witschi, H. P. Enhanced tumour development by butylated hydroxytoluene (BHT) in the liver, lung and gastro-intestinal tract. Food Chem. Toxicol. 1986, 24 (10-11), 1127-1130.

(12) Oikawa, S.; Nishino, K.; Oikawa, S.; Inoue, S.; Mizutani, T.; Kawanishi, S. Oxidative DNA damage and apoptosis induced by metabolites of butylated hydroxytoluene. Biochem. Pharmacol. 1998, 56 (3), 361-370.

(13) Nilsson, A.; Lagesson, V.; Bornehag, C. G.; Sundell, J.; Tagesson, C. Quantitative determination of volatile organic compounds in indoor dust using gas chromatography-UV spectrometry. Environ. Int. 2005, 31 (8), 1141-1148.

(14) Rodil, R.; Quintana, J. B.; Basaglia, G.; Pietrogrande, M. C.; Cela, R. Determination of synthetic phenolic antioxidants and their metabolites in water samples by downscaled solid-phase extraction, silylation and gas chromatography-mass spectrometry. J. Chromatogr. A 2010, 1217 (41), 6428-6435.
(15) Weschler, C. J.; Nazaroff, W. W. Dermal uptake of organic vapors commonly found in indoor air. Environ. Sci. Technol. 2014, 48 (2), 1230-1237.

(16) Fries, E.; Püttmann, W. Monitoring of the antioxidant BHT and its metabolite BHT-CHO in German river water and ground water. Sci. Total Environ. 2004, 319 (1-3), 269-282.

(17) Hernández, F.; Portolés, T.; Ibáñez, M.; Bustos-López, M. C.; Díaz, R.; Botero-Coy, A. M.; Fuentes, C. L.; Peñuela, G. Use of timeof-flight mass spectrometry for large screening of organic pollutants in surface waters and soils from a rice production area in Colombia. Sci. Total Environ. 2012, 439, 249-59.

(18) Andreu, V.; Ferrer, E.; Rubio, J. L.; Font, G.; Pico, Y. Quantitative determination of octylphenol, nonylphenol, alkylphenol ethoxylates and alcohol ethoxylates by pressurized liquid extraction and liquid chromatography-mass spectrometry in soils treated with sewage sludges. Sci. Total Environ. 2007, 378 (1-2), 124-129.

(19) Butte, W.; Hoffmann, W.; Hostrup, O.; Schmidt, A.; Walker, G. Endocrine disrupting chemicals in house dust: results of a representative monitoring. Gefahrstoffe - Reinhalt. L. 2001, 61 (1-2), $19-23$.

(20) Gao, Y. L.; Gu, Y. X.; Wei, Y. Determination of polymer additives-antioxidants and ultraviolet (UV) absorbers by highperformance liquid chromatography coupled with UV photodiode array detection in food simulants. J. Agric. Food Chem. 2011, 59 (24), 12982-12989.

(21) Jeannot, G.; Sabik, H.; Sauvard, H.; Dagnac, T.; Dohrendorf, K. Determination of endocrine-disrupting compounds in environmental samples using gas and liquid chromatography with mass spectrometry. J. Chromatogr. A 2002, 974 (1-2), 143-159.

(22) Soliman, M. A.; Pedersen, J. A.; Park, H.; Castaneda-Jimenez, A.; Stenstrom, M. K.; Suffet, I. H. Human pharmaceuticals, antioxidants, and plasticizers in wastewater treatment plant and water reclamation plant effluents. Water Environ. Res. 2007, 79 (2), 156-167.

(23) US EPA (2011). Estimation Programs Interface Suite v4.10. United States Environmental Protection Agency, DC, USA.

(24) Collings, A. J.; Sharratt, M. The BHT content of human adipose tissue. Food Cosmet. Toxicol. 1970, 8 (4), 409-412.

(25) Nemoto, S.; Omura, K.; Takatsuki, S.; Sasaki, K.; Toyoda, M. Determination of 2,4,6-tri-tert-butylphenol and related compounds in foods. J. Food Hyg. Soc. Jpn. 2001, 42 (6), 359-366.

(26) Adolfsson-Erici, M.; Åkerman, G.; McLachlan, M. S. Measuring bioconcentration factors in fish using exposure to multiple chemicals and internal benchmarking to correct for growth dilution. Environ. Toxicol. Chem. 2012, 31 (8), 1853-1860.

(27) Organization for Economic Co-operation and Development. Available online at http://webnet.oecd.org/hpv/ui/Default.aspx (accessed on July 21, 2014).

(28) U.S. Environmental Protection Agency. Available online at http://www.epa.gov/oppt/existingchemicals/pubs/workplans.html (accessed on July 21, 2014).

(29) Bolz, U.; Hagenmaier, H.; Korner, W. Phenolic xenoestrogens in surface water, sediment, and sewage sludge from Baden-württemberg, south-west Germany. Environ. Pollut. 2001, 115 (2), 291-301.

(30) Jobling, S.; Reynolds, T.; White, R.; Parker, M. G.; Sumpter, J. P. A variety of environmentally persistent chemicals, including some phthalate plasticizer, are weakly estrogenic. Environ. Health Perspect. 1995, 103 (6), 582-587.

(31) U.S. Environmental Protection Agency. Available online at http://water.epa.gov/scitech/drinkingwater/dws/ccl/ccl3.cfm (accessed on July 21, 2014).

(32) Du, F.; Guo, F. U. Research progress in antioxidant of bridged alkyl phenols category and its derivates used for synthetic rubber. China Synth. Rubber Ind. 2009, 32 (4), 352-354.

(33) Matsuo, M.; Mihara, K.; Okuno, M.; Ohkawa, H.; Miyamoto, J. Comparative metabolism of 3,5-di-tert-butyl-4-hydroxytoluene (BHT) in mice and rats. Food Chem. Toxicol. 1984, 22 (5), 345-354.

(34) Fumiko, N.; Ushiyama, K.; Kano, I. DNA cleavage by metabolites of butylated hydroxytoluene. Arch. Toxicol. 1993, 67 (8), $552-557$. 
(35) Rodil, R.; Quintana, J. B.; Cela, R. Oxidation of synthetic phenolic antioxidants during water chlorination. J. Hazard. Mater. 2012, 199-200, 73-81.

(36) Organization for Economic Co-operation and Development. Available online at http://www.oecd.org/chemicalsafety/riskassessment/oecdpovandlrtpscreeningtool.htm (accessed on July 21, 2014).

(37) Wang, T.; Lou, S. Y. Actuality census and technical economy value about urban wastewater treatment technology. Water Wastewater Eng. 2004, 20 (5), 1-4.

(38) Zeng, L. X.; Li, H. J.; Wang, T.; Gao, Y.; Xiao, K.; Du, Y. G.; Wang, Y. W.; Jiang, G. B. Behavior, fate, and mass loading of short chain chlorinated paraffins in an advanced municipal sewage treatment plant. Environ. Sci. Technol. 2013, 47 (2), 732-740.

(39) Song, S. J.; Ruan, T.; Wang, T.; Liu, R. Z.; Jiang, G. B. Occurrence and removal of benzotriazole ultraviolet stabilizers in a wastewater treatment plant in China. Environ. Sci. Proc. Impacts 2014, 16 (5), 1076-1082.

(40) Saito, M.; Sakagami, H.; Fujisawa, S. Cytotoxicity and apoptosis induction by butylated hydroxyanisole (BHA) and butylated hydroxytoluene (BHT). Anticancer Res. 2003, 23 (6C), 4693-4701. 